\title{
MAKNA RITUAL KHANDURI BUNGONG KAYÉE DALAM MASYARAKAT LHOK PAWOH KEC. SAWANG KAB. ACEH SELATAN
}

\author{
Muhibbul Subhi ${ }^{1}$, Muhajir Al-Fairusy ${ }^{2}$, Muhammad Nasir ${ }^{3}$ \\ 1, 3. Teuku Umar University, Aceh, Indonesia \\ ${ }^{2}$ Faculty of Dakwah, STAIN Teungku Dirundeng Meulaboh, Aceh, Indonesia
}

Korespondensi: muhibbulsubhi@utu.ac.id

\begin{abstract}
The khanduri bungong kayée ritual is an activity of the people in Lhok Pawoh in carrying out an annual ceremony with the aim of obtaining blessings from Allah the Almighty so that all fruitful plants survive from animal disturbances and other things that can abort bungong kayée (wooden flowers), so this bungong kayée can be a fruit that benefits the local community. The problems in this study are: 1) What is the ritual process of khanduri bungong kayée in the Lhok Pawoh community? 2) What is the symbolic meaning of the khanduri bungong kayée ritual procession in Lhok Pawoh?. This research is a field research using a descriptive analyst approach, which analyzes a number of social phenomena conducted by the people of Lhok Pawoh in the khanduri bungong kayée ritual. The data collection technique in this paper is through observation, interviews and documentation. Informants in this study are people who know about the khanduri bungong kayée ritual such as traditional leaders, religious leaders, intellectuals and ordinary people. The results of the study indicate that this blessing is done by reading Al-Qur'an by the reciters who have been invited. Then proceed with the shamadiyah and pray is led by teungku imuem meunasah Lhok Pawoh. The meaning of incense burning in the khanduri bungong kayée ritual is to scent a special place. The meaning of reading the holy verses of the Qur'an is intended by the local community for the safety of old plants of all kinds of diseases which can abort the wooden flowers (bungong kayée). While the meaning expected by the Lhok Pawoh community in the process of supporting orphans is that Allah SWT always bestows on His grace and sustenance to them through the prayers that are guaranteed by orphans. From the results of the study the authors conclude that the blessings of bungong kayée conducted by the Lhok Pawoh community have an impact on the religious aspect, namely the increasing sense of our love for the holy verses of the Qur'an and orphans. In addition to the religious aspects, this issue also has an impact on the social aspects, namely the increasing relationship between local residents and other villagers.
\end{abstract}

Keywords: meaning, ritual, Khanduri Bungong Kayée. 
Aceh Anthropological Journal,

Abstrak: Studi ini mendiskusikan ritual khanduri bungong kayée, tradisi yang berlangsung di tengah masyarakat Lhok Pawoh, Aceh Selatan. Tradisi ini bertujuan untuk meminta keberkahan bagi sang pencipta, guna menyuburkan tanaman yang sudah berbuah, dan selamat dari hama dan gangguan lain yang dapat menggugurkan bungong kayée (bunga kayu). Bunga kayu sebagai cikal buah dipandang pembawa manfaat oleh masyarakat tempatan. Penelitian ini beranjak dari pertanyaan, bagaimana prosesi ritual khanduri bungong kayée dalam masyarakat Lhok Pawoh dan apa makna simbolis terhadap prosesi ritual khanduri bungong kayée bagi masyarakat setempat. Penelitian ini menggunakan analis deskriptif, menganalisis fenomena sosial masyarakat Lhok Pawoh dalam ritual khanduri bungong kayée. Data diperoleh dari informan yang mengetahui tentang ritual khanduri bungong kayée; tokoh adat, tokoh agama, cendikiawan dan masyarakat biasa. Hasil penelitian menunjukkan bahwa khanduri ini melibatkan simbol-simbol agamam Islam, dimulai dengan membaca kitab suci al-Qur'an. Kemudian dilanjutkan dengan ritual shamadiyah yang dipimpin oleh agamawan setempat. Selain itu, dilakukan pula pembakaran kemenyan, dengan tujuan mengharumkan lokasi ritual. Tradisi ini ditutup dengan penyantunan pada anak yatim, yang dimaknai sebagai upaya meminta keberhakan melalui perantara anak yatim, sebagai kelompok manusia yang dianggap wajib untuk disantuni dalam ajaran Islam jika menginginkan keberkahan dan rezeki melimpah.

Kata kunci: Makna, Ritual, Khanduri Bungong Kayée 


\section{A. PENDAHULUAN}

Dalam banyak kebudayaan yang berkembang di Aceh, sering dijumpai ritual adat istiadat dalam bentuk khanduri, baik khanduri yang dilaksanakan secara kolektif maupun individual, di mana kedua khanduri tersebut memiliki makna filosofis dan tujuan yang beraneka ragam. Hal demikian bisa dilihat dalam prosesi ritual adat istiadat yang dilakukan oleh masyarakat Aceh Selatan dalam berbagai macam khanduri, seperti khanduri blang (kenduri sawah), khanduri jeurat (kenduri kuburan), khanduri laot (kenduri laut), khanduri bungong kayée (kenduri bunga kayu) dan lain sebagainya yang layak dipertahankan karena proses pelaksanaannya sudah banyak mengandung unsur-unsur Islam di dalamnya. Hal tersebut bisa dilihat dari pembacaan ayat suci Al quran, shamadiyah dan doa yang dilakukan oleh masyarakat Desa Lhok Pawoh dalam sejumlah khanduri.

Ajaran Islam dan adat dalam pandangan masyarakat Aceh merupakan dua sisi mata uang yang sama sekali tidak dapat dipisahkan. Filosofi pemahaman seperti ini dapat ditemukan dalam ungkapan kearifan yang sangat populer dan senantiasa terpelihara eksistensi dalam kehidupan masyarakat. Ungkapan tersebut bisa dilihat dalam narit maja (hadih maja) "Hukom ngon adat lagee zat ngon sifeuet" Ini semua dimaksudkan bahwa semua ketentuan ajaran Islam atau hukum Islam telah melekat dengan nilai-nilai adat yang terdapat dalam masyarakat Aceh.

Joko Tri Prasetya ketika mengemukakan pendapatnya Yousselin De Yong, menyebutkan bahwa pengaruh Islam terhadap kebudayaan Indonesia bersifat damai dan membangun. Seperti pengaruh-pengaruh agama Islam dalam perkawinan, warisan, hak-hak wanita dan lain-lain. Joko Tri Prasetya sependapat dengan analisis Yousselin De Yong tersebut yang mengatakan bahwa pengaruh Islam tidak hanya pada kepercayaan dan adat istiadat sehari-hari, bahkan bidang hukum dan upacara-upacara misalnya: hari-hari besar Islam, upacara kematian, selamatan-selamatan dalam upacara perkawinan, mengubur mayat, do'a, wakaf, warisan, letak masjid dan sebagainya. Dengan demikian dapat dipahami bahwa Islam adalah satu-satunya agama yang lengkap sehingga banyak sumber adat istiadat dan kebudayaan diambil darinya, yang kemudian hari diimprementasikan oleh masyarakat dalam kehidupan sehari-hari. 
Dalam kehidupan sosial kemasyarakatan, penduduk Desa Lhok Pawoh sering melakukan sebuah kebudayaan dalam bentuk ritual khanduri bungong kayée. Perkembangan khanduri bungong kayée dalam masyarakat Lhok Pawoh pada umumnya sama halnya dengan perkembangan khanduri bungong kayée di tempat lain, yaitu melalui lisan ke lisan. Eksistensi khanduri ini masih dilakukan sampai saat ini dikarenakan banyaknya tanaman tua yang dapat dijadikan oleh masyarakat setempat sebagai sumber rezeki.

Khanduri tersebut telah melekat dalam diri masyarakat setempat dari tahun ke tahun dan senantiasa memasukkan unsur-unsur Islam dalam proses pelaksanaannya. Hal ini sesuai dengan narit maja yang memberi penegasan terhadap adat dengan ajaran Islam, yaitu "adat ngon hukom lage zat ngon sifeuet", maksudnya adalah bangunan dari nilai-nilai adat istiadat yang dikembangkan dan dilestarikan di Aceh tidak berdiri sendiri, namun harus menyatu dan tidak dapat dipisahkan dengan nilai-nilai Islam. Begitu juga dengan khanduri bungong kayée yang merupakan bagian dari adat istiadat masyarakat Aceh Selatan yang tidak bisa dipisahkan dari unsur-unsur Islam di dalam proses pelaksanaannya.

Berdasarkan suatu tujuan untuk memahami permasalahan dalam penelitian ini, maka studi akan difokuskan untuk melihat peran aktor, dan gambaran umum prosesi ritual khanduri bungong kayée dalam masyarakat Desa Lhok Pawoh sehingga berdampak pada sistem sosial dan keagamaan masyarakat setempat. Selain itu, studi ini juga akan menganalisis secara mendalam tentang makna filosofis yang terkandung dalam sejumlah simbol-simbol pada prosesi ritual khanduri bungong kayée.

\section{B. METODE PENELITIAN}

Penelitian ini dilakukan untuk mengkaji adat istiadat yang ada di masyarakat Desa Lhok Pawoh. Desa ini terletak di jalan Nasional Tapaktuan dan Blang Pidie. Secara tipologi desa ini terletak sangat dekat dengan pesisir pantai dan penggunungan, sehingga memudahkan masyarakat setempat untuk menggali sumber ekonomi dalam dua sektor, yaitu bidang tanaman dan perikanan. Alasan memilih Desa Lhok Pawoh sebagai lokasi penelitian adalah untuk melihat budaya, 
dan kehidupan masyarakat diluar budaya peneliti sangat dianjurkan dalam studi antropologi, sehingga akan menghasilkan sebuah etnografi di luar kacamata budaya peneliti yang bersifat emik. Kedua, kehidupan masyarakat Desa Lhok Pawoh dan adat istiadat yang terdapat di dalamnya jarang diekspose dalam studi sosial di Aceh. Apalagi, budaya dan adat istiadat masyarakat Desa Lhok Pawoh di sana sangat berorientasi pada hubungan sosial kemasyarakat dan keagamaan.

Penelitian ini merupakan penelitian lapangan (case study), dengan menggunakan pendekatan analisis deskriptif. Penelitian deskriptif ini merupakan penelitian yang benar-benar hanya memaparkan apa yang terdapat atau terjadi dalam sebuah lapangan, atau di suatu tempat. Adapun data yang akan dikumpulkan menggunakan pendekatan motede penelitian kualitatif, agar menjamin kualitas dan kedalaman data nantinya. Pengumpulan data dilakukan dengan membaca beberapa literatur ilmiah yang berkaitan dengan topik yang penulis teliti. Kedua, metode pengamatan terlibat (participant observation), ketiga, wawancara dan dolumentasi. beranjak dari metode pengumpulan data, agar dapat memahami adat istiadat masyarakat Desa Lhok Pawoh, maka peneliti menetap bersama masyarakat untuk beberapa bulan. Tahapan terakhir dalam penelitian ini adalah analisis data, guna menentukan gambaran etnografi yang baik dari ketajaman analisis dari seorang peneliti. Menurut Spradley analisis selalu dikerjakan dalam kaitannya dengan permasalahan yang asli serta hipotesis yang khusus. dalam penelitian ilmu sosial, penelitian tidak boleh mengubah permasalahan yang diteliti bersamaan dengan pengumpulan data, karena hal ini akan merusak hasil daripada penelitian. Data yang telah terkumpul dalam penelitian kemudian diklasifikasikan (dikelompokkan) kembali menurut jenis, sifat atau kondisinya. Sesudah datanya dianggap lengkap baru kemudian dibuat suatu kesimpulan.

\section{HASIL DAN PEMBAHASAN}

\section{Prosesi ritual khanduri bungong kayée}

Koentjaraningrat mendefinisikan kenduri (makan bersama) dengan suatu unsur yang penting dalam upacara keagamaan. Dalam upacara itu yang diundang 
adalah orang laki-laki tetangga. Upacara dilakukan oleh teungku atau teungku meunasah, orang-orang yang paham akan ayat-ayat Alquran. Para undangan didudukkan di atas tikar di serambi depan rumah. Kemudian tuan rumah menyampaikan maksud upacara kenduri tersebut. Penyampaian doa dimulai, dan doa biasanya ditentukan dalam bentuk berzikir kepada Allah Swt. Sebelum berzikir dihidangkan di depan para tamu makanan dan lauk pauk yang cukup banyak. Setelah semuanya selesai, baru disudahi dengan berdoa dan selawat kepada Nabi Muhammad Saw. upacara kenduri ini biasa dilakukan sebagai unsurunsur dalam upacara sekitar lingkaran individu dan upacara kematian.

Hal demikian juga berlaku di Aceh di mana semua orang yang hadir dalam upacara khanduri duduk di atas tikar yang telah disediakan oleh panitia. Setelah semua hadir dan duduk di atas tikar, teungku imuem meunasah mengambil sejumlah kemenyan untuk dibakar. Pembakaran kemenyan tersebut dapat dimaknai sebagai penanda akan dimulainya upacara ritual shamadiyah dalam suatu khanduri.

Ritual khanduri bungong kayée dilaksanakan oleh masyarakat Desa Lhok Pawoh pada bulan Jumadil Akhir. Masyarakat setempat beranggapan bahwa bulan tersebut sebagai bulan khanduri bungong kayée, karena kebanyakan keluarnya bungong kayée pada bulan ini. Prosesi khanduri tersebut dilaksanakan dari jam 09:00 WIB sampai dengan selesai dan diawali dengan cara membacakan sejumlah ayat suci Al-Qur'an oleh 12 orang qari yang diundang oleh panitia khanduri. Prosesi pembukaan ayat suci Al-Qura'an pertama kali dipimpin oleh imuem meunasah dengan mengucapkan:

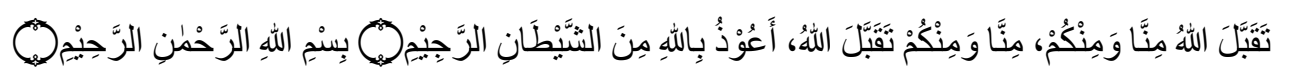

Kemudian dilanjutkan dengan membaca sejumlah ayat suci Al-Qur'an sampai dengan selesai.

Setelah pembacaan ayat suci Al-Qur'an selesai dilaksanakan, teungku imuem meunasah kembali melanjutkan prosesi khanduri bungong kayée dengan membaca ritual shamadiyah yang diikuti oleh semua orang yang hadir dalam acara khanduri tersebut. Pembukaan shamadiyah kadang-kadang dipimpin oleh teungku yang diundang serta memiliki usia lebih tua dari teungku lainnya. Pembacaan shamadiyah di desa ini sama halnya dengan Pembacaan shamadiyah di tempat- 
tempat lain dalam kawasan Aceh selatan, yaitu dengan mengucapkan.

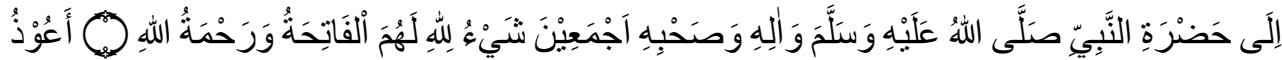

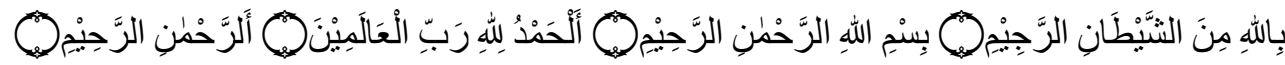

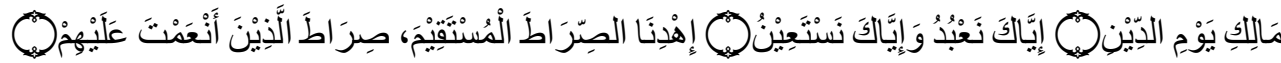

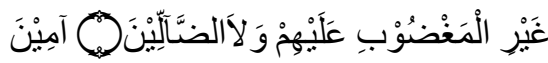

Setelah do'a tersebut selesai dibaca, maka selanjutnya teungku pimpinan shamadiyah langsung membacakan surat Al-Iklas sebanyak $10 \mathrm{x}$.

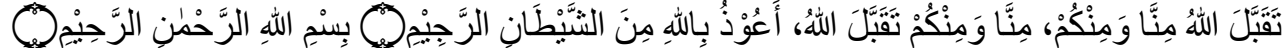

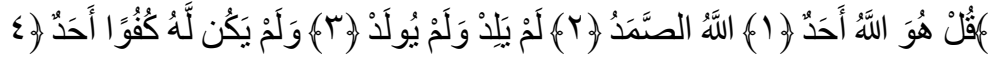

Seterusnya dilanjutkan dengan pembacaan surat Al-Falaq sebanyak $1 \mathrm{x}$.

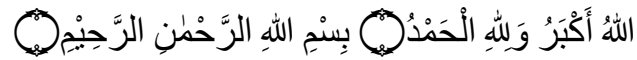

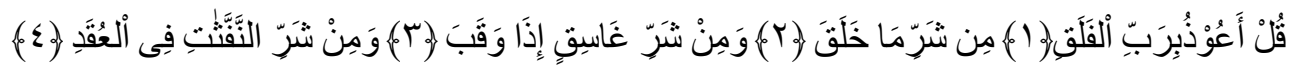

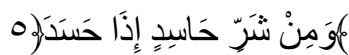

Kemudian teungku pimpinan shamadiyah melanjutkan dengan membaca surat An-Nas sebanyak $1 \mathrm{x}$.

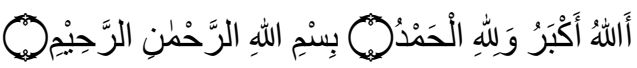

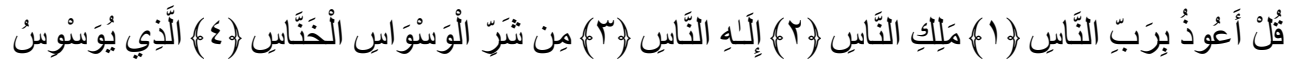

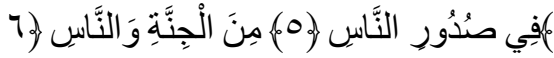

Tahap selanjutnya setelah semua surat selesai dibaca oleh teungku. Teungku pimpinan shamadiyah melanjutkan ritual tersebut dengan membacakan sejumlah zikir kepada Allah Swt dengan mengucapkan:

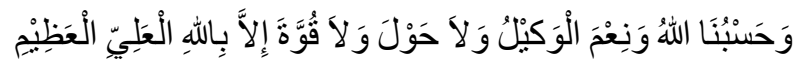

Dilanjutkan dengan pembacaan istighfal sebanyak 3 x.

$$
\text { أَسْتَغْفْرُ اللهَ الْعَظِْيََْ }
$$

Kemudian diakhiri dengan pembacaan zikir La ilaha illa llah sebanyak 33 x.

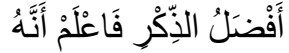

$$
\begin{aligned}
& \text { لاَّ إلَِهَ إِلاًَ اللهُ }
\end{aligned}
$$

Kemudian teungku pimpinan ritual shamadiyah menutup prosesi tersebut dengan serangkain do'a. Secara umum do'a yang dibacakan dalam khanduri bungong kayée meliputi do'a keberkatan rezeki, do’a pengampunan dosa, do'a keselamatan dunia dan akhirat dan lain sebagainya. 


\section{Makna filosofis ritual khanduri bungong kayée}

Dalam sistem kebudayaan, semua objek hasil kebudayaan merupakan produk yang dihasilkan oleh kemampuan manusia menggunakan lambang. Dalam sistem kehidupan keagamaan, simbol sebagai tanda dapat memberikan beberapa pengertian, diantaranya simbol merupakan cara pengenalan yang bersifat khas relegius. Hal demikian bisa dilihat pada sidik jari manusia yang tidak akan sama dengan miliyaran manusia lainnya. Hal ini ternyata telah Allah sebutkan dalam AlQur'an surat Al-Qiyamah ayat 3-4 yang artinya:

"Apakah manusia mengira bahwa kami akan mengumpulkan (kembali) tulang belulangnya ? (Bahkan) kami mampu menyusun (kembali) jari jemarinya dengan sempurna", (QS Al-Qiyamah ayat 3-4).

Dari hasil pengamatan di lapangan terdapat 3 makna filosofis dalam ritual khanduri bungong kayée di Desa Lhok Pawoh. Ketiga Makna simbol tersebut memiliki makna tersendiri dan dapat dilihat di bawah ini:

1. Makna Simbol Ritual Pembakaran Kemenyan

Thomas F. O'dea mendefinisikan ritual sebagai transformasi simbolik dan pengalaman-pengalaman yang tidak dapat diungkapkan tepat oleh media lain. Karena berasal dari kebutuhan primer manusia, maka ia merupakan kegiatan yang spontan dalam arti betapun peliknya, ia lahir tanpa niat, tanpa disesuaikan dengan sesuatu tujuan yang disadari, pertumbuhannya tanpa rancangan, polanya benarbenar alamiah.

Dalam khanduri bungong kayée yang dilakukan masyarakat Desa Lhok Pawoh ritual pembakaran kemenyan dilakukan setelah prosesi pembacaan ayat suci Al-Qur'an. Dalam proses pembakaran kemenyan masyarakat setempat telah menyiapkan bahan-bahan sebagai berikut:

a. Tempat kecil, yaitu sebuah mangkok kecil yang digunakan untuk memasukkan tanah, arang dan kemenyan.

b. Tanah, tanah ini digunakan untuk meletakkan arang yang sudah dibakar.

c. Arang, arang ini berfungsi sebagai bahan untuk membakar kemenyan.

d. Kemenyan, kemenyan ini diletakkan di atas arang yang sudah terbakar sehingga mengeluarkan asap yang sangat wangi. 
Mengenai do'a yang sering dibacakan dalam ritual khanduri bungong kayée penulis mewawancarai seorang teungku pimpinan pondok Pesantren Syamsul Mu'arif. Teungku Sukardi menjelaskan bahwa do'a dalam prosesi pembakaran kemenyan sebagai berikut:

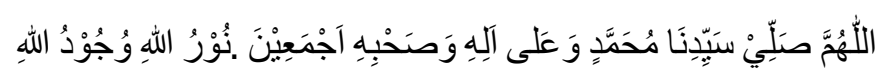

Dari hasil wawancara dengan sejumlah tokoh agama yang ada di Desa Lhok Pawoh, mereka mengatakan bahwa makna pembakaran kemenyan dalam khanduri bungong kayée adalah untuk mengharumkan sebuah ruangan (tempat khanduri) yang diyakini oleh masyarakat setempat akan hadirnya para malaikat.

2. Makna Simbol Pembacaan Al-Qur'an

Prosesi pembacaan Al-Qur'an sangat bermakna bagi masyarakat Desa Lhok Pawoh, seperti halnya dapat mendorong minat anak-anak untuk belajar qiraat dan tilawah kepada qari qariah yang ada di Aceh Selatan. Selain makna tersebut, lantunan ayat suci Al-Qur'an juga dapat menambah iman seseorang. Hal ini sangat jelas Allah sebutkan dalam surat Al-Anfal ayat 2 yang artinya:

“Sesungguhnya orang-orang yang beriman adalah mereka yang apabila disebutkan nama Allah gemetar hatinya, dan apabila dibacakan ayat-ayatNya kepada mereka, bertambah (kuat) imannya dan hanya kepada Tuhan mereka bertawakal". (QS surat Al-Anfal ayat 2).

Dari penjelasan ayat di atas penulis menganalisis bahwa pembacaan ayat suci Al-Qur'an dalam ritual khanduri bungong kayée sangat bermakna religius, yaitu sebagai ajang untuk memperdengarkan lantunan ayat suci Al-Qur'an kepada seluruh masyarakat yang hadir dalam khanduri tersebut agar keimanan mereka kepada Allah semakin bertambah serta dapat meningkatkan praktek-praktek keagamaan secara berjamaah seperti shalat, zikir, majelis ilmu dan sebagainya.

Secara umum makna filosofis yang terdapat dalam ritual pembacaan ayat suci Al-Qur'an bisa dilihat sebagai berikut:

a. Diniatkan oleh masyarakat setempat untuk keselamatan tanaman tua dari segala macam penyakit serta hal-hal lain yang dapat menggugurkan bunga tanaman (Aceh; bungong kayée).

b. Diniatkan pahala bacaan Al-Qur'an kepada orang tua mereka yang telah 
meninggal.

c. Diniatkan pahala bacaan Al-Qur'an kepada masyarakat Desa Lhok Pawoh agar dijauhkan atas segala macam bencana.

Hal ini sesuai dengan hadis Nabi Muhammad Saw yang artinya:

“Dari Umar radhiallahu'anhu, bahwa Rasulullah shallallahu'alaihi wa sallam bersabda, "Amal itu tergantung niatnya, dan seseorang hanya mendapatkan sesuai niatnya", (HR Bukhari dan Muslim).

3. Makna Simbol Penyantunan Anak Yatim

Sudah sepatutnya seseorang agar selalu memiliki sifat sosial yang tinggi dalam melihat dan berbaur dengan anak yatim dari keterbatasan yang mereka miliki. Hal ini sesuai dengan perintah Allah dalam surat An-Nisa ayat 36.

"Sembahlah Allah dan janganlah kamu mempersekutukanNya dengan sesuatupun. Dan berbuat baiklah kepada dua orang ibu-bapak, karib-kerabat, anak-anak yatim, orang-orang miskin". (QS An-Nisa ayat 36)

Selain uang sedekah, masyarakat Desa Lhok Pawoh juga membagikan sejumlah nasi kepada anak yatim, bahkan ada sebahagian masyarakat setempat rela mengantarkan satu buah rantangan nasi kepada anak yatim yang berada di desa lain. Hal ini juga telah disebutkan Allah Swt dalam surat Al-Ihsan ayat 8.

"Dan mereka memberikan makanan yang disukainya kepada orang miskin, anak yatim dan orang yang ditawan". (QS Al-Insan ayat 8).

Anak yatim yang diundang dalam khanduri bungong kayée kebanyakan usianya masih anak-anak (belum baligh) dan diyakini oleh masyarakat setempat bersih dari dosa besar dan kecil sehingga do'a mereka cepat dikabulkan oleh Allah Swt. Hal ini sesuai dengan tulisan Abdul Manan yang menjelaskan bahwa tujuan diundangnya anak-anak dalam ritual khanduri bungong kayée adalah agar do'a mereka dikabulkan oleh Allah Swt karena anak-anak tersebut seperti malaikat, tidak pernah melakukan dosa dan tidak bersalah. Dengan alasan inilah mengapa Allah Mengirim rahmat ke bumi dan jika anak-anak melakukan suatu kebaikan seperti shalat maka mereka akan mendapatkan pahala dari Allah dan pahala itu akan diberikan kepada orang tuanya.

Makna filosofis yang terdapat dalam prosesi penyantunan anak yatim adalah sebagai berikut: 
a. Agar Allah Swt senantiasa melimpahkan rahmat dan rezekiNya kepada masyarakat setempat melalui tanaman tua.

b. Memohon kepada Allah Swt agar tanaman tua masyarakat setempat dijauhkan dari segala macam penyakit.

c. Memohon kepada Allah Swt agar bunga tanaman tua diselamatkan oleh Allah sampai masa panen.

\section{PENUTUP}

Berdasarkan dari apa yang telah penulis uraikan di atas, maka penulis dapat menyimpulkan bahwa ritual khanduri bungong kayée dalam masyarakat Desa Lhok Pawoh Kecamatan Sawang sebagai berikut:

Khanduri bungong kayée adalah sebuah khanduri yang dilakakuan oleh masyarakat Desa Lhok Pawoh dalam rangka menyambut datangnya bulan Jumadil Akhir. Masyarakat Desa Lhok Pawoh beranggapan bahwa bulan tersebut sebagai bulan khanduri bungong kayée, karena kebanyakan keluarnya bungong kayée pada bulan ini.

Proses pelaksanaan ritual khanduri bungong kayée mulai dilakukan oleh masyarakat Desa Lhok Pawoh pada pukul 09:00 pagi dengan membacakan sejumlah ayat suci Al-Qur'an. Ritual pembacaan shamadiyah dan do'a diikuti oleh semua orang dengan mengucapkan surat Al-Fatihah sebanyak 1 kali dan dilanjutkan dengan surat Al-Ikhlas sebanyak 10 kali, surat Al-Falaq 1 kali dan AnNas 1 kali, kemudian ditutup dengan mengulangi bacaan surat Al-Fatihah sebanyak 1 kali. Selanjutnya teungku pimpinan shamadiyah membacakan zikir Astaghfiru Ilahal 'azim sebanyak 3 kali dan La Ilaha Ill Allah 33 kali, terakhir ditutup dengan pembacaan do'a yang dibacakan oleh teungku imuem meunasah Desa Lhok Pawoh.

Makna pembakaran kemenyan dalam ritual khanduri bungong kayée adalah untuk sumber wangi-wangian serta untuk mengharumkan sebuah ruangan tempat khanduri yang diyakini dapat menghadirkan para malaikat. Untuk pembacaan ayat suci Al-Qur'an dalam ritual khanduri bungong kayée sangat bermakna religius, yaitu dapat meningkatkan keimanan seseorang apabila mendengarkannya (Lihat QS Al-Anfal ayat 2). Selain itu, pembacaan ayat suci Al-Qur'an juga bisa diniatkan untuk keselamatan tanaman tua dari segala macam penyakit yang dapat 
menggugurkan bunga kayu (Aceh bungong kayée). Sedangkan makna filosofis prosesi penyantunan anak yatim sangat bermakna sosial keagamaan. Hal ini bisa dilihat dalam proses pembagian amplop kepada anak yatim yang sangat bermakna sosial sehingga dapat diimprementasikan oleh seluruh masyarakat dalam kehidupan sehari-hari. Selain makna di atas, masyarakat setempat juga meminta kepada anak yatim untuk senantiasa berdo'a kepada Allah Swt agar semua tanaman tua dijauhkan dari segala macam penyakit dan hal-hal lain yang dapat menggugurkan bunga kayu.

\section{Daftar Pustaka}

Abdullah Sani, Ridwan. 2015. Sains Berbasis Al-Qur'an, Edisi Kedua, Jakarta: Bumi Aksara.

Arikunto, Suharsimi. 2010. Prosedur Penelitian: Suatu Pendekatan Praktik, Jakarta: Rineka Cipta.

Ismail, Badruzzaman (ed). 2018. Eksiklopedia Budaya Adat Aceh. Banda Aceh: Majelis Adat Aceh.

Koentjaraningrat. 2007. Manusia dan Kebudayaan di Indonesia, cet, 22 , Jakarta: Djambatan.

Manan, Abdul. 2012. Ritual Kalender Aneuk Jamee di Aceh Selatan: Studi Etnografi di Kecamatan Labuhan Haji Barat. Jilid 1. Banda Aceh: Arraniry Press.

Muhammad, Nurdinah (ed). 2007. Antropologi Agama. Banda Aceh: Ar-Raniry Press.

Nazir, Moh. 2005. Metode Penelitian. Jakarta: Ghalia Indonesia.

NK, Mahdi (ed). 2012. Menuju Masyarakat Etis, Banda Aceh: Dinas Syariat Islam Provinsi Aceh.

Prasetya, Joko Tri. (ed). 1991. Ilmu Budaya Dasar. Jakarta: Rineka Cipta.

Semiawan, Conny R. 2010. Metode Penelitian Kualitatif, Jakarta: Grasindo.

Spradley, James P. 1997. Metode Etnografi, Yogyakarta: PT Tiara Wacana Yogya.

Sugiyono. 2010. Memahami Penelitian Kualitatif, cet keenam, Bandung: Alfabeta.

Thomas F. O'dea. 1994. Sosiologi Agama Suatu Pengantar Awal, Jakarta: Raja Grafindo Persada.

Tim Peneliti IAIN Ar-Raniry dan Biro Keistimewaan Aceh, Kelembagaan Adat Provinsi Nanggroe Aceh Darussalam, Banda Aceh: Ar-Raniry Press, t.t. 